\title{
Factors affecting the prevalence of chronic diseases in Palestinian people: an analysis of data from the Palestinian Central Bureau of Statistics
}

H.F. Abukhdeir, ${ }^{7}$ L.S. Caplan, ${ }^{7}$ L. Reese ${ }^{7}$ and E. Alema-Mensah'

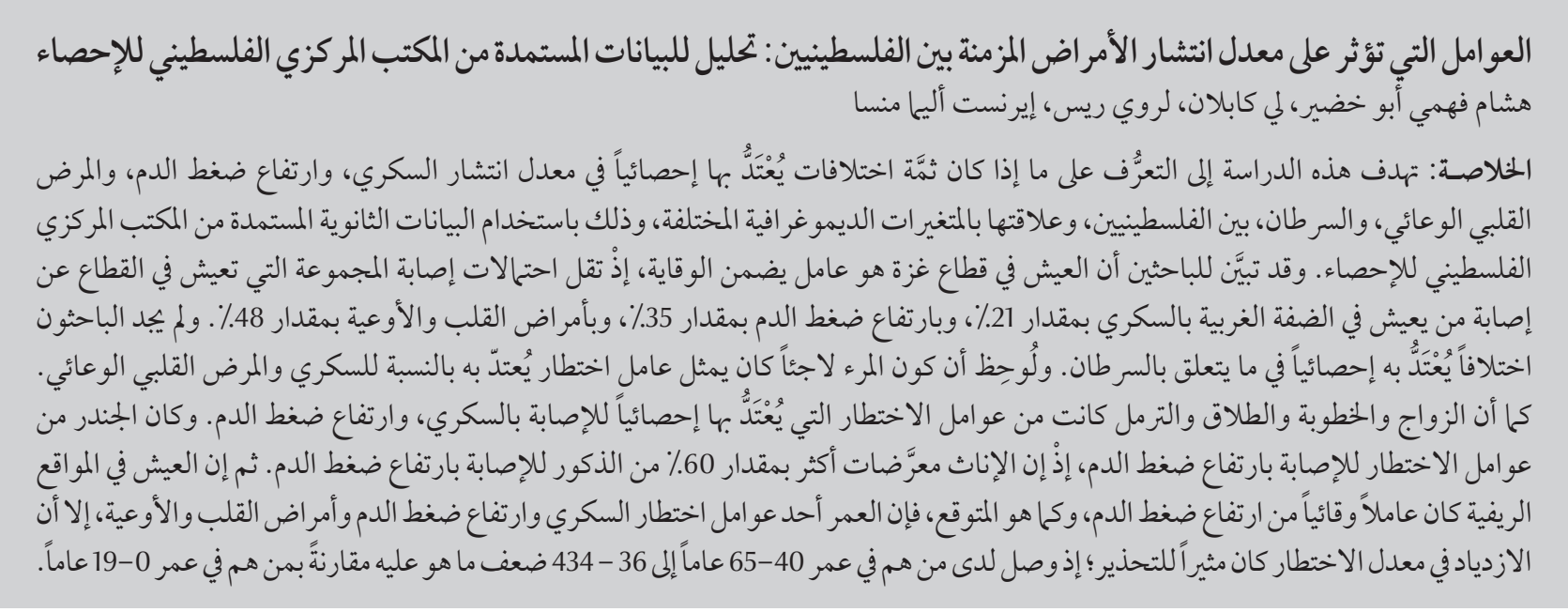

ABSTRACT This study determined whether there are significant differences in the prevalence of diabetes, hypertension, cardiovascular disease (CVD) and cancer among Palestinians with respect to different demographic variables using secondary data from the Palestinian Central Bureau of Statistics. Living in the Gaza Strip was a protective factor, with this group being $21 \%$ less likely to have diabetes, $35 \%$ less likely to have hypertension, and $48 \%$ less likely to have CVD than those living in the West Bank. No significant difference was found for cancer. Being a refugee was a significant risk factor for diabetes and CVD while being married/engaged or divorced/ separated/widowed was a risk factor for diabetes and hypertension. Gender was a risk factor for hypertension with females being $60 \%$ more likely to have hypertension than males. Living in a rural setting was protective against hypertension. As expected, age was a risk factor for diabetes, hypertension and CVD; the magnitude of this increased risk was alarming, 36 to 434 times greater in those aged 40-65 years compared with those aged 0-19 years.

Facteurs affectant la prévalence des maladies chroniques dans la population palestinienne : analyse des données du Bureau central palestinien des statistiques

RÉSUMÉ La présente étude a déterminé l'existence ou l'absence de différences significatives dans la prévalence du diabète, de l'hypertension, des maladies cardio-vasculaires et du cancer chez les Palestiniens par rapport à différentes variables démographiques, à l'aide de données secondaires du Bureau central palestinien des statistiques. Vivre dans la Bande de Gaza était un facteur de protection, car ce groupe avait $21 \%$ moins de risque d'avoir un diabète, $35 \%$ moins de risque de souffrir d'hypertension et $48 \%$ moins de risque d'être atteint d'une maladie cardio-vasculaire que la population cisjordanienne. Aucune différence significative n'a été observée pour le cancer. Être un réfugié représentait un facteur de risque pour le diabète et les maladies cardio-vasculaires, alors que le fait d'être marié/fiancé ou divorcé/ séparé/veuf était un facteur de risque pour le diabète et l'hypertension. Être une femme était un facteur de risque pour I'hypertension, celles-ci étant 60 \% plus susceptibles d'en souffrir que les hommes. Vivre en milieu rural était un facteur de protection contre l'hypertension. Comme on pouvait s'y attendre, l'âge était un facteur de risque pour le diabète, I'hypertension et les maladies cardio-vasculaires; l'ampleur de ce risque était alarmante : les Palestiniens âgés de 40 à 65 ans présentaient un risque 36 à 434 fois plus élevé que ceux âgés de 0 à 19 ans pour ces trois problèmes de santé.

'Morehouse School of Medicine, Atlanta, Georgia, United States of America (Correspondence to H.F. Abukhdeir: heshamabukhdeir@gmail.com). Received: 19/06/11; accepted: 11/02/11 


\section{Introduction}

There are currently 3 separate communities of Palestinians: those living in the West Bank, those living in the Gaza Strip, and those living in Israel. Palestinians living in Israel are under Israeli rule, while those living in the West Bank and Gaza Strip are under Fatah and Hamas rule respectively. Fatah and Hamas have separate health care systems to provide medical care to their citizens. The disease epidemiology of Palestinians is undergoing rapid change as noncommunicable diseases such as diabetes, hypertension, cardiovascular disease (CVD) and cancer are replacing communicable diseases as the main causes of morbidity and mortality [1].

Due to the unavailability of data on Palestinians living in Israel, this study compared Palestinians living in the West Bank and the Gaza Strip. These 2 groups are in fact 1 population separated by geographic and political boundaries. The differences between them with respect to overall quality of health have never been examined extensively.

This study compared the effect of a number of factors, including location, on the prevalence of chronic diseases in Palestinians living in the Gaza Strip and the West Bank using data from the Palestinian Central Bureau of Statistics.

\section{Methods}

This study used existing data sets to describe the current health status of the Palestinian people across 2 distinct environmental contexts. Secondary data from the Palestinian Central Bureau of Statistics [2] were obtained. The data had been collected using cross-sectional surveys to gather general health information on the populations of the Palestinian territories. The surveys contained questions asking respondents whether they had been diagnosed with certain diseases, including diabetes, hypertension, CVD, and cancer. The survey questionnaire was designed to be answered by a head of household, who provided information for all other family members. In the absence of the head of household, the person with the highest authority in the household was interviewed.

The target population of the Palestinian Central Bureau of Statistics survey was all Palestinian households within the West Bank and the Gaza Strip. The sampling frame was 260 enumerated areas constructed from the Population, Housing, and Establishment Census 1997 [3]. These enumerated areas were geographic regions similar in size, each containing an average of 150 households. The enumerated areas were divided into smaller units called cells containing an average of 25 households, with 1 cell per enumerated area being surveyed. For the part of Jerusalem that was annexed by Israel after the 1967 war, 30 households were selected from each enumerated area. Interviews were carried out by mobile teams between 20 May 2004 and 7 July 2004.

The number of households in the sample was 6574: 4456 in the West Bank and 2118 in the Gaza Strip. The response rates for the 2 regions were $84.1 \%$ and $96.9 \%$ respectively [2].

\section{Statistical analysis}

The dependent variables in this study were presence or absence of diabetes, hypertension, CVD and cancer. The independent variables included region, sex, returnee status, refugee status, school attendance status, educational attainment, labour force status, smoking status, number of cigarettes smoked daily, marital status, locality type, age grouping, and type of health insurance.

Region defined where the respondent lived and was categorized into the West Bank and the Gaza Strip. Returnee status defined those surveyed as being a returnee or a non-returnee. A returnee is someone who returned to Palestine after moving to another country during times of war. Educational attainment was a measure of the level of education attained by the respondent. Locality type (domicile) was categorized as urban, rural, and refugee camp. Age was categorized into young people (0-19 years), young adults (20-39 years), older adults (40-64 years) and seniors (65+ years).

Frequency distributions were run on each of these variables to ensure they were representative of the population. Bivariate analyses were performed comparing each of the independent variables with each of the dependent variables, and chi-squared analysis was used to determine any statistically significant associations.

The results were used to guide the selection of independent variables to be included in the logistic regression models, which were constructed to determine the effects of each of the independent variables on the prevalence of diabetes, hypertension, CVD and cancer, controlling for all the other variables in the models.

All analyses were conducted using SPSS, version 17.0. $P<0.05$ was considered statistically significant.

\section{Results}

The prevalence of diabetes, hypertension, CVD and cancer are shown in Figure 1. People living in the Gaza Strip were less likely to have diabetes, hypertension and CVD than those living in the West Bank.

Table 1 shows the results of the bivariate analyses performed for diabetes, hypertension, CVD and cancer. Females were more than twice as likely to have hypertension as males and were also more likely to have diabetes. Those who had never attended school were about 3 to 4 times more likely to have diabetes, hypertension and CVD and twice as likely to have cancer as those who attended school and either dropped out or graduated. Those who were illiterate were 4 or more times 


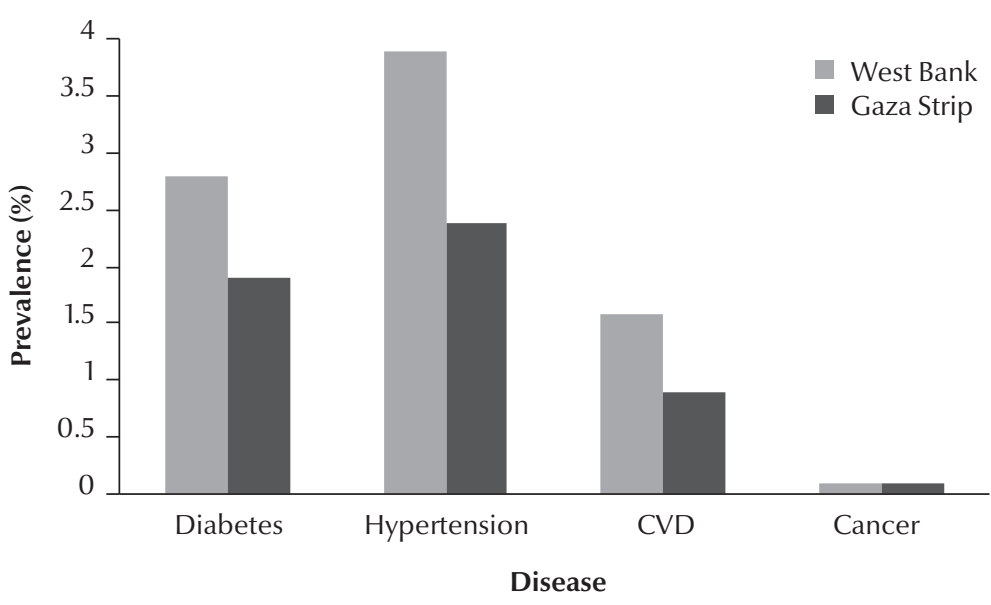

Figure 1 Disease prevalence in the West Bank and the Gaza Strip, 2004 (CVD = cardiovascular disease)

more likely to have diabetes, hypertension, CVD and cancer than those with higher levels of educational attainment. Those who were unemployed were at least 3 times more likely to have all 4 diseases compared to employed people. Ex-smokers were about 4 times more likely to have diabetes, 3 times as likely to have hypertension, 7 times as likely to have CVD, and 7 times as likely to have cancer as those who had never smoked. Prevalence of all 4 diseases increased in those who smoked at least 40 cigarettes a day.

Those who were divorced/widowed/separated were many times more likely to have diabetes, hypertension or CVD than those in the other marital status categories and 50 times as likely to have cancer as single people. Seniors were about twice as likely to have diabetes, hypertension, and cancer and about 3.5 times more likely to have CVD than older adults, who were in turn much more likely to have these diseases than those under 40 years old.

Table 2 shows the results of the multivariate modelling using logistic regression. None of the variables for cancer were statistically significant, thus, only the results for diabetes, hypertension and CVD are shown. Females were $60 \%$ more likely to have hypertension than males. Non-refugees were $33 \%$ less likely to have diabetes and $46 \%$ less likely to have CVD than refugees. Full time students were $90 \%$ less likely to have hypertension and $80 \%$ less likely to have CVD than unemployed people. People involved full-time in household chores were about $25 \%$ less likely to have diabetes and hypertension and $37 \%$ less likely to have CVD. People living in the Gaza strip were about 21\% less likely to have diabetes, $35 \%$ less likely to have hypertension, and $48 \%$ less likely to have CVD than people living in the West Bank.

Being married/engaged was shown to be a significant risk factor for diabetes and hypertension, with the odds of each of these diseases being about 2.9 and 2.6 times as high, respectively compared with single people. The odds of having diabetes and hypertension were over 3.5 times as high in divorced/widowed/ separated as in single people, and this was statistically significant $(P<0.0001)$.

Those living in a rural setting were $23 \%$ less likely to have hypertension. The odds of diabetes, hypertension and CVD tended to increase with increasing age.

Having Ministry of Health insurance was a significant risk factor for diabetes and CVD and having Israeli health insurance was a significant risk factor for diabetes and hypertension, while having Social Welfare Health insurance was a significant risk factor for diabetes, hypertension, and CVD.

\section{Discussion}

This study was unique in that it focused on comparing the Palestinians living in the West Bank and the Gaza Strip as 2 different entities, as opposed to lumping all the Palestinians together. Husseini et al.'s study on cardiovascular diseases, diabetes mellitus, and cancer did give some prevalence statistics comparing the Gaza Strip and the West Bank, but they were limited to people over 40 years who were registered refugees [1]. Given the fact that each region is controlled by a different political party and that the effects of this extend all the way to the health systems, it seems more appropriate to consider the 2 groups separately.

Our results showed significant differences in the prevalence of cancer, hypertension, CVD and diabetes between Palestinians living in the Gaza Strip and those in the West Bank, with those living in the Gaza Strip having a lower prevalence of all 4 diseases. Further studies are required to understand these findings because data from the Food and Agriculture Organization of the United Nations (2003) state that the Gaza Strip has a higher rate of food insecurity, is poorer, and has an overall lower socioeconomic status [4].

Being a refugee tended to be a risk factor, as would be expected. Refugees often live with poor housing conditions, which are not favourable to long term healthy outcomes [5].

Smoking is a proven risk factor for diabetes, CVD, and cancer and is associated with hypertension, so its protective effect against hypertension in this study is surprising [4]. Smoking in this culture has many different uses. For many people, it is way to feel accepted, or to show off, or is a response to peer pressure 


\begin{tabular}{|c|c|c|c|c|c|c|c|c|}
\hline \multirow[t]{2}{*}{ Factor } & \multicolumn{2}{|c|}{ Diabetes } & \multicolumn{2}{|c|}{ Hypertension } & \multicolumn{2}{|c|}{ CVD } & \multicolumn{2}{|c|}{ Cancer } \\
\hline & No. & $\%$ & No. & $\%$ & No. & $\%$ & No. & $\%$ \\
\hline \multicolumn{9}{|l|}{ Region } \\
\hline West Bank & 570 & 2.8 & 802 & 3.9 & 337 & 1.6 & 21 & 0.1 \\
\hline Gaza Strip & 247 & 1.9 & 306 & 2.4 & 112 & 0.9 & 13 & 0.1 \\
\hline$P$-value & \multicolumn{2}{|c|}{0.0001} & \multicolumn{2}{|c|}{0.0001} & \multicolumn{2}{|c|}{0.0001} & \multicolumn{2}{|c|}{0.981} \\
\hline \multicolumn{9}{|l|}{ Sex } \\
\hline Male & 374 & 2.2 & 367 & 2.2 & 214 & 1.3 & 19 & 0.1 \\
\hline Female & 443 & 2.7 & 741 & 4.5 & 235 & 1.4 & 15 & 0.1 \\
\hline$P$-value & \multicolumn{2}{|c|}{0.005} & \multicolumn{2}{|c|}{0.0001} & \multicolumn{2}{|c|}{0.205} & \multicolumn{2}{|c|}{0.54} \\
\hline \multicolumn{9}{|l|}{ Returnee status } \\
\hline Returnee & 16 & 3.4 & 20 & 4.2 & 7 & 1.5 & 3 & 0.6 \\
\hline Non-returnee & 801 & 2.4 & 1088 & 3.3 & 442 & 1.3 & 31 & 0.1 \\
\hline$P$-value & \multicolumn{2}{|c|}{0.201} & \multicolumn{2}{|c|}{0.289} & \multicolumn{2}{|c|}{0.821} & \multicolumn{2}{|c|}{0.013} \\
\hline \multicolumn{9}{|l|}{ Refugee status } \\
\hline Refugee & 365 & 2.6 & 471 & 3.3 & 208 & 1.4 & 19 & 0.1 \\
\hline Non-refugee & 452 & 2.4 & 637 & 3.4 & 241 & 1.3 & 15 & 0.1 \\
\hline$P$-value & \multicolumn{2}{|c|}{0.318} & & & & & & \\
\hline School attendance status & & & & & & & & \\
\hline Currently attending school & 10 & 0.1 & 7 & 0.1 & 12 & 0.1 & 3 & 0.01 \\
\hline Attended school and dropped out & 292 & 4.4 & 379 & 5.7 & 148 & 2.2 & 10 & 0.2 \\
\hline Attended school and graduated & 247 & 3.7 & 311 & 4.6 & 113 & 1.7 & 11 & 0.2 \\
\hline Never attended school & 263 & 11.1 & 409 & 17.3 & 165 & 7.0 & 9 & 0.4 \\
\hline$P$-value & & & & & & & & \\
\hline Educational attainment & & & & & & & & \\
\hline Illiterate & 268 & 16.9 & 418 & 26.3 & 165 & 10.4 & 7 & 0.4 \\
\hline Can read or write & 140 & 4.0 & 179 & 5.1 & 77 & 2.2 & 5 & 0.1 \\
\hline Elementary ${ }^{a}$ & 161 & 2.7 & 211 & 3.6 & 85 & 1.4 & 4 & 0.1 \\
\hline Preparatory ${ }^{b}$ & 106 & 1.7 & 128 & 2.0 & 48 & 0.8 & 6 & 0.1 \\
\hline Secondary & 61 & 1.7 & 84 & 2.3 & 27 & 0.7 & 2 & 0.1 \\
\hline Intermediate associated level diploma ${ }^{c}$ & 39 & 4.1 & 46 & 4.9 & 14 & 1.5 & 3 & 0.3 \\
\hline Bachelor degree & 34 & 2.5 & 39 & 2.9 & 14 & 1.0 & 2 & 0.1 \\
\hline$P$-value & & & & & & & & \\
\hline Work status $^{d}$ & & & & & & & & \\
\hline Employed & 151 & 2.9 & 164 & 3.1 & 57 & 1.1 & 7 & 0.1 \\
\hline Unemployed & 371 & 9.3 & 480 & 12.0 & 252 & 6.3 & 15 & 0.4 \\
\hline Full-time student & 4 & 0.01 & 1 & 0.01 & 4 & 0.01 & 1 & 0.01 \\
\hline Involved full time in household chores & 283 & 4.9 & 460 & 7.9 & 117 & 2.0 & 6 & 0.1 \\
\hline$P$-value & & & & & & & & \\
\hline Smoking status ${ }^{d}$ & & & & & & & & \\
\hline Mostly cigarettes & 130 & 3.5 & 119 & 3.2 & 70 & 1.9 & 9 & 0.2 \\
\hline Mostly pipe/hookah & 17 & 5.4 & 28 & 8.9 & 9 & 2.9 & 1 & 0.3 \\
\hline Ex-smoker & 74 & 12.1 & 76 & 12.4 & 67 & 10.9 & 4 & 0.7 \\
\hline Never smoked & 588 & 3.2 & 882 & 4.7 & 284 & 1.5 & 15 & 0.1 \\
\hline$P$-value & & & & & & & & \\
\hline
\end{tabular}




\begin{tabular}{|c|c|c|c|c|c|c|c|c|}
\hline \multirow[t]{2}{*}{ Factor } & \multicolumn{2}{|c|}{ Diabetes } & \multicolumn{2}{|c|}{ Hypertension } & \multicolumn{2}{|c|}{ CVD } & \multicolumn{2}{|c|}{ Cancer } \\
\hline & No. & $\%$ & No. & $\%$ & No. & $\%$ & No. & $\%$ \\
\hline \multicolumn{9}{|l|}{ No. cigarettes/day $(n=130$} \\
\hline$\leq 10$ & 25 & 3.0 & 23 & 2.8 & 14 & 1.7 & 2 & 0.2 \\
\hline $11-20$ & 54 & 2.8 & 43 & 2.3 & 25 & 1.3 & 4 & 0.2 \\
\hline $21-40$ & 41 & 4.8 & 44 & 5.2 & 25 & 2.9 & 3 & 0.4 \\
\hline $40+$ & 10 & 6.3 & 9 & 5.7 & 6 & 3.8 & 0 & 0 \\
\hline$P$-value & \multicolumn{2}{|c|}{0.01} & \multicolumn{2}{|c|}{0.001} & \multicolumn{2}{|c|}{0.008} & \multicolumn{2}{|c|}{0.824} \\
\hline \multicolumn{9}{|l|}{ Marital status ${ }^{e}$} \\
\hline Single & 20 & 0.2 & 34 & 0.4 & 25 & 0.3 & 2 & 0.01 \\
\hline Engaged/married & 624 & 5.5 & 784 & 7.0 & 299 & 2.7 & 22 & 0.2 \\
\hline Divorced/widowed/separated & 163 & 17.7 & 287 & 31.2 & 106 & 11.5 & 5 & 0.5 \\
\hline$P$-value & \multicolumn{2}{|c|}{0.0001} & \multicolumn{2}{|c|}{0.0001} & \multicolumn{2}{|c|}{0.0001} & \multicolumn{2}{|c|}{0.0001} \\
\hline \multicolumn{9}{|l|}{ Locality type } \\
\hline Urban & 472 & 2.6 & 654 & 3.5 & 243 & 1.3 & 22 & 0.1 \\
\hline Rural & 210 & 2.3 & 291 & 3.2 & 140 & 1.5 & 3 & 0.01 \\
\hline Camp & 135 & 2.4 & 163 & 2.9 & 66 & 1.2 & 9 & 0.2 \\
\hline$P$-value & \multicolumn{2}{|c|}{0.351} & \multicolumn{2}{|c|}{0.035} & \multicolumn{2}{|c|}{0.182} & \multicolumn{2}{|c|}{0.034} \\
\hline \multicolumn{9}{|l|}{ Age group (years) } \\
\hline Young people (0-19) & 12 & 0.1 & 5 & 0.01 & 23 & 0.1 & 6 & 0.01 \\
\hline Young adults (20-39) & 47 & 0.5 & 77 & 0.8 & 31 & 0.3 & 3 & 0.01 \\
\hline Older adults(40-64) & 510 & 11.4 & 633 & 14.1 & 204 & 4.5 & 16 & 0.4 \\
\hline Senior (65+) & 248 & 20.9 & 393 & 33.1 & 191 & 16.1 & 9 & 0.8 \\
\hline$P$-value & \multicolumn{2}{|c|}{0.0001} & \multicolumn{2}{|c|}{0.0001} & \multicolumn{2}{|c|}{0.0001} & \multicolumn{2}{|c|}{0.0001} \\
\hline \multicolumn{9}{|l|}{ Type of health insurance } \\
\hline Ministry of Health & 322 & 2.9 & 402 & 3.7 & 184 & 1.7 & 12 & 0.1 \\
\hline Military & 25 & 1.8 & 26 & 1.9 & 8 & 0.6 & 2 & 0.1 \\
\hline UNRWA & 211 & 2.1 & 273 & 2.7 & 121 & 1.2 & 9 & 0.1 \\
\hline Social welfare/elderly & 52 & 6.2 & 89 & 10.6 & 35 & 4.2 & 3 & 0.4 \\
\hline Israeli & 72 & 3.7 & 97 & 5.0 & 24 & 1.2 & 4 & 0.2 \\
\hline Private/from abroad & 14 & 2.4 & 15 & 2.6 & 8 & 1.4 & 1 & 0.2 \\
\hline None & 120 & 1.6 & 204 & 2.7 & 67 & 0.9 & 3 & 0.01 \\
\hline$P$-value & \multicolumn{2}{|c|}{0.0001} & \multicolumn{2}{|c|}{0.0001} & & & & \\
\hline
\end{tabular}

ancludes kindergarten through 5 th grade; children under 5 years old not included.

${ }^{b}$ Includes 6th through 8th grade.

'A 2-year degree awarded after secondary school.

'Includes only those aged $\geq 10$ years.

e' Includes only those aged $\geq 12$ years.

[6]. It is also used as an escape from everyday life, a stress reliever. This may explain its surprisingly protective effect on hypertension, as those who smoke may use it as psychological escape from their troubles [6]. Few people see it as a risk factor owing to the number of older people who smoke. They do not realize that these long-time smokers have health problems.
Being an ex-smoker was associated with a higher prevalence for CVD. Exsmokers may have had additional stress as a result of their quitting, and they may have begun eating as an outlet for their addiction. Being an ex-smoker was associated with a higher prevalence for CVD. Smoking cessation has been linked to an increase in obesity and diabetes, both of which are risk factors for CVD [7]. These findings could be the focus of a new study in the region dealing with the perceptions of smoking and its repercussions.

Being married has been shown to be a protective factor for cancer and CVD [8]. Considering that hypertension and diabetes are predisposing factors to CVD and some types of cancer, presumably, marriage would 


\begin{tabular}{|c|c|c|c|}
\hline Factor & Diabetes & Hypertension & CVD \\
\hline & $\begin{array}{l}\text { Adjusted for all variables } \\
\text { OR }(95 \% \mathrm{Cl})\end{array}$ & $\begin{array}{c}\text { Adjusted for all variables } \\
\text { OR }(95 \% \mathrm{CI})\end{array}$ & $\begin{array}{l}\text { Adjusted for all variables } \\
\text { OR }(95 \% \mathrm{CI})\end{array}$ \\
\hline \multicolumn{4}{|l|}{ Region } \\
\hline West Bank & 1.000 & 1.000 & 1.000 \\
\hline Gaza Strip & $0.785(0.658-0.936)^{* *}$ & $0.646(0.548-0.762)^{* * * *}$ & $0.522(0.411-0.662)^{* * * *}$ \\
\hline \multicolumn{4}{|l|}{ Sex } \\
\hline Male & 1.000 & 1.000 & 1.000 \\
\hline Female & - & $1.585(0.269-1.980)^{* * * *}$ & - \\
\hline \multicolumn{4}{|l|}{ Refugee status } \\
\hline Refugee & 1.000 & 1.000 & 1.000 \\
\hline Non-refugee & $0.658(0.552-0.784)^{* * * *}$ & - & $0.539(0.428-0.677)^{* * * *}$ \\
\hline \multicolumn{4}{|l|}{ Work status } \\
\hline Unemployed & 1.000 & 1.000 & 1.000 \\
\hline Employed & $0.519(0.418-0.646)^{* * * *}$ & $0.548(0.443-0.678)^{* * * *}$ & $0.339(0.247-0.465)^{* * * *}$ \\
\hline Full-time student & - & $0.100(0.014-0.733)^{*}$ & $0.207(0.074-0.583)^{* *}$ \\
\hline $\begin{array}{l}\text { Involved full time in } \\
\text { household chores }\end{array}$ & $0.782(0.651-0.938)^{* *}$ & $0.751(0.606-0.930)^{* *}$ & $0.630(0.491-0810)^{* * * *}$ \\
\hline \multicolumn{4}{|l|}{ Smoking status } \\
\hline Never smoked & 1.000 & 1.000 & 1.000 \\
\hline Mostly cigarettes & - & $0.538(0.428-0.676)^{* * * *}$ & - \\
\hline Mostly pipe/hookah & - & $1.571(1.001-2.466)^{*}$ & - \\
\hline Ex-smoker & - & & $2.603(1.920-3.529)^{* * * *}$ \\
\hline \multicolumn{4}{|l|}{ Marital status } \\
\hline Single & 1.000 & 1.000 & 1.000 \\
\hline Married/engaged & $2.918(1.825-4.666)^{* * * *}$ & $2.634(1.800-3.854)^{* * * *}$ & - \\
\hline $\begin{array}{l}\text { Divorced/widowed/ } \\
\text { separated }\end{array}$ & $3.631(2.195-6.008)^{* * * *}$ & $3.735(2.492-5.597)^{* * * *}$ & - \\
\hline \multicolumn{4}{|l|}{ Locality type } \\
\hline Urban & 1.000 & 1.000 & 1.000 \\
\hline Rural & - & $0.777(0.657-0.920)^{* *}$ & - \\
\hline \multicolumn{4}{|l|}{ Age group (years) } \\
\hline Young people (0-19) & 1.000 & 1.000 & 1.000 \\
\hline Young adult (20-39) & $4.783(2.269-10.083)^{* * * *}$ & $14.511(5.522-38.132)^{* * * *}$ & $3.186(1.810-5.608)^{* * * *}$ \\
\hline Older adult (40-64) & $89.878(43.338-186.397)^{* * * *}$ & $209.604(80.631-544.878)^{* * * *}$ & $35.655(22.254-57.126)^{* * * *}$ \\
\hline Senior $(65+)$ & $138.141(65.978-289.231)^{* * * *}$ & $433.597(166.186-1131.302)^{* * * *}$ & $95.047(59.819-151,021)^{* * * *}$ \\
\hline \multicolumn{4}{|l|}{ Type of health insurance } \\
\hline None & 1.000 & 1.000 & 1.000 \\
\hline Ministry of Health & $1.563(1.302-1.877)^{* * * *}$ & - & $1.607(1.277-2022)^{* * * *}$ \\
\hline Social Welfare & $1.708(1.225-2.381)^{* *}$ & $2.049(1.546-2.716)^{* * * *}$ & $1.958(1.316-2.913)^{* * *}$ \\
\hline Israeli & $1.819(1.362-2.428)^{* * * *}$ & $1.406(1.087-1.818)^{* *}$ & - \\
\hline
\end{tabular}

${ }^{*} P<0.05 ;{ }^{*} P<0.01 ;{ }^{* *} P<0.001 ;{ }^{* * *} P<0.0001$.

$-=$ not statistically significant.

$C V D=$ cardiovascular disease $; O R=$ odds ratio; $C I=$ confidence interval.

have similar protective effects against them. We found that people who were married/engaged were almost 3 times as likely and that people who were separated, divorced, or widowed were almost 4 times as likely to have diabetes and hypertension as single individuals The impact of marriage, divorce, and the lifestyles associated with them on chronic diseases is an area of study that requires more investigation and is out of scope for this paper. 
We found that living in a rural environment was protective against hypertension. Living in a rural environment allows for an easier ability to grow food and cost of living is lower [9]. Meat is not the primary source of protein as it is expensive. These slightly better living conditions could be the reason for the protective effect.

Having any type of health insurance was associated with a higher prevalence of all diseases. However, it does not seem plausible that a person without health insurance would pay out of pocket on a consistent enough basis to be diagnosed with a chronic disease. Even if this were the case, it is a very difficult assumption to make for every person without health insurance, which would be necessary for this result to be accurate. The latter would also have to be true: those with insurance have to be getting consistent enough care to be diagnosed with a chronic disease. A questionnaire accompanied by medical tests would clear up many of these questions and should be the goal for future studies."

As would be expected, older people had higher disease prevalence than younger people for all 3 diseases. However, the degree to which being older was a risk factor was quite alarming, with those aged 40-65 years and over being anywhere from 36 to 434 times as likely as people aged $0-19$ years to have diabetes, hypertension, or CVD. This, coupled with the fact that quality of health care has been decreasing since 2000 is very frightening for this age group [10].

A major strength of this study was that it compared Palestinians living in the Gaza Strip and the West Bank and identified the possible presence of health disparities between them. A limitation of the study was that it was limited to prevalence, as opposed to incidence data, which limited the ability to assess the risk of disease associated with potential risk factors. Another limitation was that disease data were obtained through selfreporting of medical diagnoses, which could have introduced reporting errors that might have biased the data. Despite the limitations, this study had a number of interesting results and can form the basis for future studies. In addition, it would be useful to include Palestinians living in Israel proper.

\section{Acknowledgement}

This study was part of the Master of Public Health thesis of H.F. Abukhdeir, "Palestinian public health: the effects of regional location on the prevalence of diabetes, hypertension, cardiovascular disease, and cancer", Master of Public Health Program, Morehouse School of Medicine.

\section{References}

1. Husseini A et al.Cardiovascular diseases, diabetes mellitus, and cancer in the occupied Palestinian territory. Lancet, 2009, 373:1041-1049.

2. Demographic and health survey, 2004: main findings. Ramallah, Palestine, Palestinian Central Bureau of Statistics, 2005.

3. Population, housing and establishment census 1997: marital characteristics in the Palestinian Territory. Ramallah, Palestine, Palestinian Central Bureau of Statistics, 2000.

4. How Tobacco Smoke Causes Disease: The Biology and Behavioral Basis for Smoking-Attributable Disease: A Report of the Surgeon General. Atlanta, GA: U.S. Department of Health and Human Services, Centers for Disease Control and Prevention, National Center for Chronic Disease Prevention and Health Promotion, Office on Smoking and Health, 2010.

5. Al-Khatib I A, Tabakhna H. Housing conditions and health in Jalazone Refugee Camp in Palestine. Eastern Mediterranean Health Journal, 2006, 12(1-2):144-152.
6. Smoking and Associated Factors, in the Occupied Palestinian Territory. Birzeit, Palestine, Birzeit University, Institute of Community \& Public Health, 2010.

7. Chiolero A et al. Consequences of smoking for body weight, body fat distribution, and insulin resistance. American Journal of Clinical Nutrition, 2008, 87:801-9.

8. Jaffe $\mathrm{D}$ et al. The protective effect of marriage on mortality in a dynamic society. Annals of epidiomiology, 2007, 17(7):540-547.

9. Report of the food security assessment West Bank and Gaza Strip. Rome, Food and Agriculture Organization of the United Nations \& World Food Programme, 2003.

10. Mataria A et al. The health-care system: an assessment and reform agenda. Lancet, 2009, 373(9670):1207-1217. 